\title{
Playoff Uncertainty, Match Uncertainty and Attendance at Australian National Rugby League Matches*
}

\author{
Nicholas King, P. Dorian Owen and Rick Audas
}

This paper develops a new simulation-based measure of playoff uncertainty and investigates its contribution to modelling match attendance compared to other variants of playoff uncertainty in the existing literature. A model of match attendance that incorporates match uncertainty, playoff uncertainty, past home-team performance and other relevant control variables is fitted to Australian National Rugby League data for seasons 2004-2008 using fixed effects estimation. The results suggest that playoff uncertainty and home-team success are more important determinants of match attendance than match uncertainty. Alternative measures of playoff uncertainty based on points behind the leader, although more ad hoc, also appear able to capture the effects of playoff uncertainty.

Keywords: playoff uncertainty, match uncertainty, sports league attendance, Australian National Rugby League, fixed effects estimation

JEL classification: C23, L83

\section{Contact details:}

Dorian Owen

Department of Economics

University of Otago

PO Box 56

Dunedin 9054

New Zealand

email: Dorian.Owen@otago.ac.nz

tel: (64) 34798655

fax: (64) 34798174

\footnotetext{
* We are grateful to Dan Farhat for comments on an earlier version and advice on MATLAB coding, and to the Department of Economics, University of Otago for funding for a summer studentship.
} 


\section{Introduction}

The essence of the 'uncertainty of outcome hypothesis' (UOH) (Rottenberg, 1956) is that close sporting contests, with more uncertain outcomes, are more attractive to fans. Although empirical studies of fans' demand for sport include a wide range of explanatory variables (Borland \& Macdonald, 2003), uncertainty of outcome is usually regarded, on a priori grounds, as one of the key factors. Consequently, there is a substantial body of literature examining the $\mathrm{UOH}$ both at the aggregate level (viewing each season as an individual observation) and at a more disaggregated level (viewing each match as an observation). Considering its central role in the economic analysis of professional sports leagues, evidence on the relevance of the $\mathrm{UOH}$ is surprisingly mixed (Borland \& Macdonald, 2003; Szymanski, 2003; Downward et al., 2009). However, testing the UOH is made difficult by the challenge of measuring the different unobservable ex ante dimensions of uncertainty of outcome, including match uncertainty, seasonal uncertainty and consecutive-season uncertainty.

In this paper, we investigate the effects of uncertainty of outcome on match attendance in the Australian National Rugby League (NRL). Given the span of the data examined, we focus on match uncertainty and 'playoff uncertainty', i.e., uncertainty about which teams will finish in the top eight positions, which qualifies them for post-round-robin playoffs that determine the overall league winners. Playoff uncertainty and other aspects of seasonal uncertainty have received less attention in the literature than individual match uncertainty, but it is feasible that seasonal uncertainty has a more important effect on fan interest and attendance over the course of a season as teams drop out of contention for the top positions. 
Conventional measures of seasonal uncertainty have been relatively crude, such as counting the number of games or points behind the leader. Our approach is to derive measures of both playoff and match uncertainty using a simulation model applied to data from the NRL. Simulation methods have previously been used to predict match and tournament outcomes (e.g., Clarke, 1993; Koning et al., 2003) and to investigate the implications for attendance of different league structures or of equalizing playing talent across teams (Dobson et al., 2001; Forrest et al., 2005). However, our study constitutes one of the first attempts, along with Bojke (2008), to use simulation methods specifically to generate ex ante measures of different aspects of uncertainty of outcome.

Although there are numerous previous studies of the determinants of attendance for different sports, relatively few consider rugby league; exceptions include the studies by Baimbridge et al. (1995), Carmichael et al. (1999), Jones et al. (2000) and Dobson et al. (2001), which all examine attendance at English rugby league matches. Australian attendance demand studies have focused on the Australian Football League (e.g., Borland, 1987; Borland and Lye, 1992; Lenten, 2009a), with analysis of the NRL concentrating more on measurement of competitive balance (e.g., Booth, 2004; Lenten, 2009b). The unpublished paper by Alchin and Tranby (1995), which examines attendance demand for Australian rugby league using season-level data for 35 seasons (1960-1994), is an exception. Our paper therefore contributes to a currently sparse literature relating to attendance demand for rugby league in general and for the NRL in particular. ${ }^{1}$

\footnotetext{
${ }^{1}$ The NRL was formed in 1907 as the New South Wales Rugby League with the inaugural premiership held in 1908. It is now the most important rugby league championship in the Southern Hemisphere with, from 2007, ten teams from New South Wales, three from Queensland, one from Victoria, one from the Australian Capital Territory, and one from New Zealand.
} 
In Section II we provide an overview of the various measures used to quantify different dimensions of uncertainty of outcome in the existing literature testing the UOH. Section III outlines a new approach to measuring both match uncertainty and playoff uncertainty based on simulating match and end-of-season outcomes. Section IV includes the simulation-based uncertainty measures in an empirical model of attendance demand for NRL matches. Results from fitting the model to five seasons of NRL data are reported in section V, including comparisons of results for the simulation-based measure of playoff uncertainty with measures used in previous match attendance studies. Section VI concludes.

\section{Measuring Uncertainty of Outcome}

It is usual to distinguish between (at least) three different dimensions of uncertainty of outcome relating to different relevant time spans: short-run match uncertainty, mediumterm within-season uncertainty, and long-run championship uncertainty (Cairns et al., 1986; Borland and Macdonald, 2003; Szymanski, 2003).

Match uncertainty is concerned with the predictability of individual matches. It is the most frequently examined dimension of outcome uncertainty, although there is no clear consensus on the best way to measure it (Buraimo et al., 2008). Measures of match uncertainty used in the literature are generally based on two main sources of information: teams' relative performances prior to a match (as summarized in relative league positions, points totals or win percentages) or match betting odds.

Match uncertainty measures based on league positions (e.g., Hart et al., 1975; Borland and Lye, 1992; Baimbridge et al., 1996; Falter and Pérignon, 2000; García and Rodríguez, 2002; Benz et al., 2009; Madalozzo and Villar, 2009), points totals (e.g., Wilson and Sim, 1995) or win percentages of the competing teams (e.g., Welki and Zlatoper, 1999; Meehan 
et al., 2007) have their drawbacks. They do not account for home advantage (Forrest and Simmons, 2002; Buraimo et al., 2008) or the difficulty of the teams' playing schedules up to that point in the season, and they do not necessarily adequately capture current form (Sandy et al, 2004). Win percentages and league positions are likely to display greater variability early on in the season when teams have played relatively few games, so the degree to which these measures reflect teams' relative abilities will vary over the season. All these measures have also been criticized for being "entirely backward-looking" and based on partial information (Downward and Dawson, 2000, p.134).

By contrast, betting odds are regarded as incorporating a wider range of relevant information, e.g., on suspensions or injuries to players. Match uncertainty measures based on betting odds are generally expressed in the form of the probability of a home-team win (Peel and Thomas, 1988, 1992; Knowles et al., 1992; Czarnitzki and Stadtmann, 2002; Benz et al., 2009; Lemke et al., 2010) or the evenness of the contest based on the ratio of the probability of a home win to the probability of an away win (Forrest and Simmons, 2002). Although odds-based measures accord more closely with an ex ante notion of outcome uncertainty, concerns have been raised about biases in setting odds (Forrest and Simmons, 2002; Forrest et al., 2005; Buraimo et al., 2008). ${ }^{2}$ Also, the historical record for such odds may not always be available for use in empirical studies.

Despite the emphasis placed on the $\mathrm{UOH}$ in the literature, empirical results on the significance of match uncertainty are mixed. For example, of 18 studies reviewed by Borland and Macdonald (2003) only four produced clear evidence of a positive statistically significant effect of match uncertainty on attendance. This may be partly due to

\footnotetext{
${ }^{2}$ Dobson and Goddard (2008) provide a succinct but comprehensive review of recent studies of the efficiency of fixed-odds betting on football; most of the studies they review suggest that betting odds are not efficient.
} 
econometric problems such as multicollinearity and appropriately controlling for other influences. It is also possible that the difficulty in identifying significant match uncertainty effects may be partly due to measurement problems, especially as many of the measures are based on ex post information and overlap with measures of team quality or success. ${ }^{3}$ In this study, as discussed in section III, we adopt an alternative measure of match uncertainty that is neither determined purely by teams' standings nor reliant on betting odds, but is based on a match's predicted outcome and the cumulative distribution of observed errors.

Seasonal uncertainty is concerned with the degree of within-season uncertainty surrounding teams finishing in some end-of-season position, e.g., winning the championship, making the playoffs, and/or avoiding relegation. The generally held view is that, from an overall league perspective, fans are expected to prefer higher levels of uncertainty with many teams in contention throughout the season. Indeed, expanding the set of teams with a non-zero probability of end-of-season success for a greater part of the season is a primary motivation for including playoffs as an element of competition design. However, playoffs redistribute the probability of eventual success over more teams, so there is a potential trade-off between increased attendance for teams kept in contention by the existence of playoffs and decreased attendance for teams whose probability of eventual success has been consequently reduced. Overall league attendance may therefore decrease, especially if the latter are large-market teams (Bojke, 2008).

Measures of seasonal uncertainty used in the literature are usually based on the number of games a team is required to win to make the playoffs or to win the championship (e.g.,

\footnotetext{
${ }^{3}$ Downward et al. (2009), in their review of studies of short-run uncertainty of outcome, note that league standings, rather than differences in standings or odds-based measures, tend to show up as more relevant in explaining attendance. However, actual standings may be acting as a measure of team success or team quality rather than uncertainty of outcome.
} 
Jennett, 1984; Borland and Lye, 1992), the number of games (wins) or points behind the leading team (e.g., Borland, 1987; Whitney, 1988; Knowles et al., 1992; García and Rodríguez, 2002; Meehan et al., 2007; Benz et al., 2009; Lemke et al., 2010), or the significance of the match for the championship, playoffs or relegation (e.g., Jones et al., 2000; Dobson et al., 2001; Madalozzo and Villar, 2009). These measures are often used to help explain match-level attendance, with the expectation that matches between teams out of contention will attract less interest. ${ }^{4}$ The statistical significance of such variables in empirical studies tends to be somewhat stronger than measures of match uncertainty; of 19 studies reviewed by Borland and Macdonald (2003), 12 produced evidence of a statistically significant effect of seasonal uncertainty on attendance. ${ }^{5}$

Although these variables have been found to be useful in modelling match attendance, they have drawbacks as measures of ex ante uncertainty. Any measure based on the number of games a team needs to win to make the playoffs, or to win the championship, has the key weakness that the information required to generate these variables is not available at the time spectators decide whether to attend a match. Counting the number of games behind provides an indication of the feasibility of a team remaining in contention, but does not consider the difficulty of the remaining matches in the schedule either for that team or for others in contention; it can therefore provide only a rough approximation to the underlying probability. Similarly, measures based on the number of games a team is behind the current

\footnotetext{
${ }^{4}$ An alternative approach is to examine the effect of playoff uncertainty on average attendance for the league as a whole, rather than on attendance at individual matches. For example, Lee (2009) constructs a measure of average league-wide playoff uncertainty, based on aggregating team-specific information on games behind the leader.

${ }^{5}$ Downward et al. (2009) review a selection of studies that overlaps with some of those considered by Borland and Macdonald (2003). They note that the results on seasonal uncertainty are again mixed. Overall, they conclude (p. 218) that "in the shorter run at least, a team's success is at least as important as UO for determining match attendances".
} 
competition leader rely entirely on the current points table, ignore the difficulty of matches left to play, and assess how teams rank relative only to the current leader. ${ }^{6}$

Consecutive-season uncertainty refers to the absence of long-run domination by one team or a small number of teams According to the UOH, long-run domination by a few teams decreases championship uncertainty and is expected to have a negative effect on match attendance. There are relatively few studies of this dimension of uncertainty of outcome and results do not provide clear conclusions (Borland and Macdonald, 2003; Downward et al., 2009). For attendance at the level of individual matches, as in the current study, consecutive-season uncertainty has largely been ignored, primarily due to the restricted time span of such studies.

Although past studies have investigated different aspects of the UOH in some detail, measurement of the different dimensions of uncertainty of outcome leaves room for improvement. There are clearly plausible links between different dimensions of uncertainty of outcome and match attendance, but the results in the existing literature are surprisingly ambiguous on the relevance of the relationships. Uncertainty of outcome, by its very nature is concerned with the degree of predictability or unpredictability of the relevant outcome, and is therefore an ex ante concept. In contrast, most measures of uncertainty of outcome, apart from those based on betting odds, are backward-looking. In this paper we examine the relevance of measures of match and season uncertainty obtained from a consistent simulation framework that updates probability measures of match uncertainty and playoff uncertainty (the most relevant aspect of seasonal uncertainty in the NRL context) using

\footnotetext{
${ }^{6}$ In competitions with end-of-season playoffs, the number of games behind the current competition leader may not give an accurate reflection of a team's chance of making the playoffs. For example, the first-placed team may be well ahead of all the other teams; what matters then is how tight the competition is among the other teams vying for the remaining playoff positions.
} 
information available to spectators at the time of their attendance decision. This corresponds more closely to an ex ante formulation of uncertainty than used in many existing studies.

\section{Simulation-based Measures of Playoff Uncertainty and Match Uncertainty}

Our proposed measures of playoff and match uncertainty are derived by simulating the results of matches not yet played in the season. In particular, the proportion of simulated end-of-season outcomes that see each team make the playoffs provides a measure of the probability of each team making the playoffs at that point in time. A simulation-based measure of playoff uncertainty has several advantages compared to previous measures. It is not based directly on the current state of the league points table. It reflects a team's likelihood of making the playoffs relative to all other teams in the league, not just the firstplaced team. Moreover, the playoff probabilities of the various teams are consistent at every point because they are derived jointly. It takes into account the strength of the schedule, i.e., the difficulty of the remaining matches a team has to play in a season. In addition, it utilises only information available to spectators prior to the relevant match and evolves as the season progresses.

Predicted match outcomes are required to simulate sequences of results through the season. To predict match outcomes we use a framework similar to that of Stefani and Clarke (1992) and Clarke $(1993,2005)$. The outcome of each match is characterised by the home team's winning margin (points scored by the home team less points scored by the away team). The predicted home team's winning margin depends on the teams' playing strengths and the extent of home advantage: 


$$
P M_{i j, r, y}=\lambda^{H} H_{y}+S_{i, r-1, y}-S_{j, r-1, y}
$$

where $P M_{i j, r, y}$ is home team $i$ 's predicted winning margin against away team $j$, in round $r$ of year $y ; \lambda^{H}$ is a dummy variable equal to one if the match is played at a non-neutral venue and zero otherwise; $H_{y}$ is home advantage in year $y$, and $S_{i, r-1, y}$ is the strength rating for team $i$ based on information up to and including round $r-1$ of year $y .^{7}$

To allow for evolution of current form, team strength ratings are adjusted as the season progresses. For each match, the predicted outcome in equation (1) is compared with the actual match outcome, and the prediction error is calculated as

$$
E_{i j, r, y}=A M_{i j, r, y}-P M_{i j, r, y}
$$

where $E_{i j, r, y}$ is the error in the prediction of the match outcome of home team $i$ against away team $j$, in round $r$ of year $y$, and $A M_{i j, r, y}$ is the corresponding actual winning margin. Team strength ratings are updated using a simple exponential smoothing scheme:

$$
\text { Home team: } S_{i, r, y}=S_{i, r-1, y}+\gamma E_{i j, r, y}
$$

Away team: $S_{j, r, y}=S_{j, r-1, y}-\gamma E_{i j, r, y}$

where $\gamma$ is a positive constant. If the home team wins a match by more than predicted, its strength rating increases, reflecting improved form, and the away team's strength rating decreases, reflecting worsened form.

Strength ratings of all teams are set equal to zero at the beginning of the 2003 season, the season prior to the first season of observations used in fitting the attendance model in

\footnotetext{
${ }^{7} P M_{i j, r, y}<0$ corresponds to a predicted win for the away team with a points margin of $\left|P M_{i j, r, y}\right|$.
} 
section IV, and are updated as the season progresses using equation $(2) .{ }^{8}$ The parameters in the model $(\gamma$ and $H)$ are determined by minimising $\sum E_{i j, r, 2003}^{2}$, the sum of squared errors in prediction for match outcomes in 2003. The end-of-2003 strength ratings are used as initial values for the 2004 season. Strength ratings for 2004 matches are then updated, day-byday, using equation (2) and 2003 values for $\gamma$ and $H$; these strength ratings are then used in equation (1) to obtain predicted winning margins. At the end of each season, the process is repeated; i.e., the strength ratings of all teams at the beginning of season $y-1$ are set equal to zero. The parameters $\gamma$ and $H$ are obtained by minimizing the sum of squared errors in prediction in season $y-1$. The updated strength ratings provide initial values for season $y$. Strength ratings for season $y$ matches are then updated (using season $y-1$ values for $\gamma$ and $H$ ), and are used to generate predicted winning margins for matches in season $y$.

This setup assumes a homogeneous home advantage across teams within each season although this is allowed to vary between seasons. Alternative assumptions are possible (Clarke, 2005), e.g., home advantage may be different for different teams. We adopt the common home advantage formulation because the key motivation is to model spectators' ex ante uncertainty of outcomes, not necessarily to maximize prediction accuracy. The more variation in home advantage that is allowed across teams and over time, the more explanatory power can be loaded onto home advantage (with parameters $H_{i, y} ; i=1,2, \ldots$, 16 reflecting home advantage), especially with only 24 matches per team per season, but this is unlikely to reflect fans' ex ante expectations accurately. ${ }^{9}$ If we allow home

\footnotetext{
${ }^{8}$ By setting all initial values of team strength ratings equal to zero, the sum of all team strength ratings, and hence the average strength rating, are also zero at any point in time. A team's strength rating can therefore be interpreted as the expected points margin resulting from a match against an average team at a neutral venue.

${ }^{9}$ Clarke (2005) finds evidence to suggest that team-specific home advantages are significant in the Australian Football League, but year effects are not significant. However, his tests are based on fitting all the data and testing ex post for team and year effects.
} 
advantage to vary by team, we find the $H_{i}$ terms vary considerably, for any $i$, from season to season; hence, last season's team-specific home advantage is not likely to be a reliable guide to this season's team-specific home advantage. We therefore incorporate an average home-advantage adjustment (based only on the previous season's results) rather than overfitting the model and reducing the apparent ex ante uncertainty faced by spectators. ${ }^{10}$ Nonetheless, the model estimates $59 \%$ of match winners correctly and $45 \%$ of matches to within 10 points of the actual result. ${ }^{11}$

Simulated match outcomes are generated by adding a random error to the predicted match outcome:

$$
S M_{i j, r, y}=\lambda^{H} H_{y}+S_{i, r-1, y}-S_{j, r-1, y}+G E_{i j, r, y}
$$

where $S M_{i j, r, y}$ is home team $i$ 's simulated winning margin against away team $j$, in round $r$ of year $y$, and $G E_{i j, r, y}$ is the corresponding generated error. The errors are randomly drawn from a normal distribution with mean zero and a standard deviation equal to that observed in the actual errors in the fitted model. The distribution of generated errors therefore approximates the distribution of observed errors.

The measure of playoff uncertainty is based on the probability of the home team making the playoffs. This varies as the season progresses and is constructed, for each round in the season, by simulating yet-to-be-played matches to give an end-of-season points table and repeating this process 1000 times. $^{12}$ The predicted probability of the home team making the playoffs, at that point in the season, is given by the proportion of simulated

\footnotetext{
${ }^{10}$ Year effects are maintained as the model is fitted to each season's data separately. The optimised parameter values vary across seasons (with $\gamma$ values ranging from 0.047 to 0.101 and $H_{y}$ values from 1.961 to 5.620).

${ }^{11}$ This compares favourably to the $61.4 \%$ success rate in correctly predicting winning teams attained by a sports prediction website for NRL over the sample period (http://footyforecaster.com). The mean absolute value of the error in the predicted match outcome in our model is 14.37 compared to the website's 14.46.

${ }^{12}$ Within each simulation, strength ratings are updated based on the previous rounds' simulated results.
} 
end-of-season points tables for which the home team makes the playoffs. ${ }^{13}$ The predicted probability of the away team making the playoffs can be constructed in the same way. ${ }^{14}$

Our measure of match uncertainty is based on the probability of the home team winning the match. In the context of our simulation, this probability can be constructed from the predicted outcome of a match and the cumulative distribution of the observed errors in the prediction of all match outcomes. For example, suppose that, for a given match, the home team is predicted to win by $x$ points. Any error in prediction of less than $x$ points will result in the home team winning. Therefore, the proportion of observed errors less than $x$ will give a predicted probability of the home team winning the match. ${ }^{15}$

The model used to predict match and playoff probabilities was constructed using Microsoft Excel 2007. The parameter values $(\gamma$ and $H$ ) were determined, on a season-byseason basis, using the Solver function to minimise the sum of squared errors in match outcome predictions. Matlab 10 was used to simulate the results for yet-to-be-played matches as each season evolves.

This simulation-based approach provides measures of playoff uncertainty and match uncertainty jointly derived from a consistent ex ante framework. The playoff uncertainty measure, in particular, offers a potential improvement on more ad hoc measures of playoff uncertainty used in the past.

\footnotetext{
${ }^{13}$ For example, if there are five remaining rounds in a season that contains 26 pre-playoff rounds, the 21 completed rounds will give a points table reflecting actual standings at the end of 21 rounds. A simulated endof-season points table can be constructed by adding in simulated results for the final five pre-playoff rounds of matches. Repeating this process 1000 times gives 1000 simulated end-of-season points tables. The proportion of these points tables for which a team makes the playoffs gives a predicted probability, evaluated at the beginning of the $22 \mathrm{nd}$ round, of the team making the playoffs.

${ }^{14}$ Bojke (2008) uses a similar simulation approach to obtain predictions of end-of-season finishing positions and measures of game significance. However, his simulations are based on individual match betting odds for which there are some time-matching problems (Bojke, 2008, p.184).

${ }^{15}$ This method assumes there is no correlation between the predicted match outcome and the error in the predicted match outcome. Testing the correlation between these two variables reveals no significant correlation.
} 


\section{Modelling Match Attendance}

To assess the relevance of the proposed measure of playoff uncertainty, and to compare its performance with alternative measures, we model attendance at NRL matches using a conventional single-equation demand for attendance framework.

The empirical model for match attendance takes the general form

$$
\begin{array}{r}
\ln (\text { Attendance })=f(\text { Match Uncertainty, Playoff Uncertainty, WinStreak, } \\
\text { PreviousYrWin, Round, Round }{ }^{2}, \text { Sydney, Weather, Year, } \\
\text { Day of Week, Time of Day, Away Team, Home Team })+u
\end{array}
$$

The dependent variable, $\ln ($ Attendance $)$ is the natural logarithm of match attendance. The semi-log functional form provides a partial response to heterogeneity in the variation in attendance levels across teams (discussed further below), although specifying the dependent variable as Attendance does not qualitatively alter the key results. $u$ is a combined error term such that $u_{i t}=\alpha_{i}+\varepsilon_{i t}$, where $\alpha_{i}$ is a random individual-specific effect and $\varepsilon_{i t}$ an idiosyncratic error, with $i$ denoting the $i$ th home team and $t$ observations over time.

Match Uncertainty is modelled by including the probability of a home-team win, denoted PHomeWin, and its squared value, where PHomeWin for any match is based on the predicted outcome of the match and the cumulative distribution of the observed errors in the prediction of match outcomes, as discussed in section III. This allows for a quadratic relationship between the simulated home-win probability and the log of attendance, allowing an estimate of the attendance-maximizing home-win probability to be derived. Alternative formulations of the match uncertainty variable, discussed in Section V, are also considered to assess the sensitivity of the results. 
Playoff Uncertainty is the key variable of interest in this study. Our preferred measure, denoted PHomePlayoff, is the simulation-based probability of the home team making the playoffs at that stage of the season, discussed in section III. We also include the corresponding probability for the away team, PAwayPlayoff. For comparison, we also examine variants of playoff uncertainty measures used in previous studies: the number of points the home team is behind the current leader, the average number of points the home and away team are behind the current leader, and the number of points the home team requires to make the playoffs. ${ }^{16}$ We expect a positive relationship between match attendance and the probability of the home team (and, quantitatively to a lesser extent, the away team) making the playoffs. ${ }^{17}$ We expect a negative relationship between match attendance and the conventional variants of playoff uncertainty, given that spectators are expected to have increased interest in matches when the home team is closer to the current competition leader or when fewer points are required to make the playoffs.

WinStreak is defined as the number of consecutive wins (home and away) for the home team. A significant positive effect of recent home-team success on match attendance is a consistent finding of previous studies (Borland \& Macdonald, 2003). Spectators like to see their team win; we therefore expect a positive relationship between match attendance and WinStreak.

Previous YrWin is a dummy variable equal to one if the home team was the previous year's premiership winner (or zero otherwise). A positive relationship between match

\footnotetext{
${ }^{16}$ Draws, in which each team receives half of the available points, are feasible, although relatively rare in the NRL, so the number of points a team is behind the current leader is used as an alternative to the number of games a team is behind the current leader.

${ }_{17}$ Given the semi-log functional form adopted, the wider distribution of the probability of success due to playoffs can increase or decrease league-wide attendance, as suggested by Bojke (2008).
} 
attendance and PreviousYrWin is expected, reflecting increased interest in a team that has recently shown championship winning ability. ${ }^{18}$

Round, represents the number of the round in the season $(1,2, \ldots, 26)$ in which a match is played; including Round and its squared value allows the stage of the season to affect attendance, other things equal.

Sydney is a dummy variable equal to one if both playing teams are from Sydney, and zero otherwise. A positive relationship between match attendance and Sydney is expected, due to greater support for the away team than usual.

Weather represents a set of six dummy variables indicating if the weather at the match location is classified as Hot, Overcast, Windy, Rain, Showers or Cold.

Year represents a set of 1-0 dummy variables for the year in which a match took place (with 2004 as the base category). This controls for any season-specific factors that influence all teams' average attendance but are not captured by the other explanatory variables (e.g., varying average ticket prices over time). Day of Week represents a set of five 1-0 dummy variables for the day of the week a match is played (Tues, Wed, Fri, Sat, Sun, with Monday as the base category). If, for example, spectators prefer weekday matches to weekend matches, then the Day of Week dummy variables can control for this. Time of Day represents a set of 17 dummy variables for different kick-off times (with 12 noon as the base category).

Away Team consists of 15 dummy variables indicating the identity of the away team (with the Broncos as the base category) to allow for the possibility that some visiting teams

\footnotetext{
${ }^{18}$ Two other variants of this variable were also examined. The first divides the dummy variable for the previous year's winner by the round in the season. The second multiplies the dummy variable by the number of rounds left in the season. These two variants allow the effect of recent success to diminish as the season progresses. All three versions give statistically significant effects, with very minor effects on the size or statistical significance of the other estimated coefficients.
} 
are intrinsically more appealing to home fans than others. Home Team represents the teamspecific fixed effects. ${ }^{19}$

\section{$V$ Results}

The data used to fit the model in equation (3) are individual match data from the NRL for seasons $2004-2008 .^{20}$ The NRL currently hosts 16 teams following the addition of the Gold Coast Titans in 2007. Each season contains 26 rounds (apart from 2007 when there were 25 rounds) of regular-season play followed by four rounds of playoffs for the top eight ranked teams. The empirical analysis is concerned with the regular-season matches. This gives a total of 924 matches. The data therefore constitute an unbalanced panel comprising 16 cross-sectional units (the home teams) with 60 'time-series' observations for each of 15 teams, and 24 observations for the remaining team, the Titans. ${ }^{21}$ Summary statistics for the key variables of interest are provided in Table 1.

The model in equation (3) is treated as a single-equation demand function and the parameters are estimated using the fixed effects estimator, with home-team fixed effects. Fixed effects estimation assumes that the regressors are uncorrelated with the time-varying component of the equation's error term, $\varepsilon_{i t}$, but they may be correlated with the individualspecific $\alpha_{i}$ components. The random effects estimator is a feasible alternative estimator if the random effect, $\alpha_{i}$, is independently and identically distributed (iid) and the idiosyncratic

\footnotetext{
${ }^{19}$ Other relevant factors that may be captured by fixed effects include teams' historical support base, different market size of catchment areas, ease of access to match venues, stadium quality, and alternative forms of entertainment available to spectators.

${ }^{20}$ The data were obtained from http://stats.rleague.com and http://www.nrlstats.com.

${ }^{21}$ Note that, unlike many panel data sets, the observations over time are not equally spaced (because teams do not play at home every week, or even every other week) and there is a gap between seasons. Also, the timing of the observations are not aligned for all teams, as in each round some teams play at home and others play away. Conventional methods for analysing the time-series aspects of the data are therefore not necessarily appropriate; however, timing issues do not affect most of our results, unless specifically indicated.
} 
error, $\varepsilon_{i t}$, is iid, but is inconsistent under the assumptions of the fixed effects model. A common strategy to choose the estimator is to apply a Hausman pre-test of the null hypothesis that the individual effects are random, and select the fixed or random effects estimator based on the result of this pre-test. However, Guggenberger (2010) shows that such pretesting can lead to significant size distortion in subsequent testing of parameter significance; directly using $t$-statistics based on the fixed effects estimator is therefore recommended, rather than a two-stage process involving pretesting. ${ }^{22}$

Exogeneity of the regressors (with respect to $\varepsilon_{i t}$ ) would be an inappropriate assumption if, for example, higher attendance enhanced a team's available resources sufficiently to attract better players and improve the team's relative strength. However, any feedback from attendance to within-season performance and the simulated uncertainty measures is likely to be relatively minor in the current context given the focus on estimating the short-run effects of uncertainty on individual match attendance. In addition, the operation of a salary cap, although subject to breaches of varying degrees of severity, has helped to dampen any link between revenue and on-field performance. If such feedback effects are of more significance in the longer run, these may need to be considered in studies using longer time spans of data. ${ }^{23}$

Table 2 reports results for the benchmark specification, including diagnostic tests for normality, groupwise heteroskedasticity, serial correlation and cross-sectional dependence. The null of normality of the errors is not rejected at the $5 \%$ significance level based on a

\footnotetext{
${ }^{22}$ A Hausman test, derived as an $F$-statistic using cluster-robust standard errors in an auxiliary regression involving demeaned time-varying regressors (Wooldridge, 2002, p.290) strongly rejects the random effects specification $(p=0.000)$. Hence, in this application, both Guggenberger's (2010) proposed strategy and the conventional approach suggest focusing on the fixed effects estimates. In any case, random effects estimates give qualitatively similar conclusions.

${ }^{23}$ Match attendance reaches stadium capacity for only $2 \%$ of the regular-season matches in the sample, so any bias or inconsistency due to censoring of the dependent variable (with attendance at capacity, such that the number of spectators willing to pay to attend is not observable) is a minor issue.
} 
chi-squared test examining skewness and kurtosis. There is no obvious evidence of firstorder autocorrelation, using Wooldridge's (2002, pp. 282-3) test. ${ }^{24}$ On the basis of Pesaran's (2004) CD test, there is no evidence of cross-sectional dependence in the errors. This is supported by the low average absolute value of the off-diagonal elements in the matrix of residuals (denoted AvAbsCross) and by the lack of statistical significance of the Breusch-Pagan (1980) LM test applied to a balanced panel that omits the home results for the Titans. ${ }^{25}$ The modified Wald test for groupwise heteroskedasticity (Baum, 2001) strongly suggests that error variances differ across cross-sectional units, i.e., home teams. This is also apparent in Figure 1, which plots values for $\ln$ (Attendance) and their mean values for each home team. Consequently, cluster-robust standard errors are reported; these assume errors are independent across teams but allow for varying error variances across 16 clusters, i.e., by home team. ${ }^{26}$ However, using unadjusted standard errors, based on the assumption of iid errors, gives qualitatively similar conclusions for the key variables.

The main focus of interest is the size and statistical significance of the coefficients on the proxies for playoff and match uncertainty. The simulated probabilities of the home and away teams making the playoffs both have estimated effects that are statistically significant at the $0.1 \%$ level. Based on the results in Table 2, column (1), other things equal, for every increase of 0.1 in the probability that the home team will make the playoffs, match

\footnotetext{
${ }^{24}$ The time counter for the autocorrelation test results reported is based on the order of the home matches for each team. Because of the irregular nature of the time dimension of the data, 'time $t$ ' observations do not match exactly across different teams. Therefore, this result is only suggestive.

${ }^{25}$ The Breusch-Pagan test is appropriate if the time-series dimension of the panel, $T$, is greater than the number of cross-sectional units, $N$, as in our application. The Pesaran test is more appropriate for panels with large $N$ and $T$ fixed (De Hoyos and Sarafidis, 2006). Note, however, that the caveat about the irregular and unmatched timing of observations also applies to the results for both these tests; in particular, they are unlikely to fully reflect common shocks and unobserved components that lead to dependence at relatively high frequencies (e.g., less than a fortnight).

${ }^{26}$ Using bootstrap standard errors, with resampling over clusters, gives qualitatively similar results, apart from changes to the implied statistical significance of some of the time-of-match effects.
} 
attendance is estimated to increase by nearly $2 \%$. Equivalently, this corresponds to a $20 \%$ higher attendance for a team certain of making the playoffs compared to a team having no chance of making the playoffs. An increase of 0.1 in the probability that the away team will make the playoffs, other things equal, boosts match attendance by about $1 \%$.

The simulated probability of a home win is entered in quadratic form and both terms are on the margin of statistical significance at the $5 \%$ level. Based on the point estimates, the quadratic relationship between $\ln$ (Attendance) and PHomeWin has an attendancemaximizing home-win probability of 0.605 , a result in line with several previous studies for other sports (Borland and Macdonald, 2003). A quadratic relationship with significant coefficients, indicative of an inverted U-shaped relationship between home-win probability and attendance, is conventionally interpreted as supportive of the $\mathrm{UOH}$ at the level of match uncertainty; however, previous studies do not usually examine whether the marginal effect of the home-win probability is significant throughout its range of values. The 95 per cent symmetric confidence interval for the marginal effect of PHomeWin can be obtained as:

$$
\left(b_{1}+2 b_{2} \text { PHomeWin }\right) \pm 1.96\left[\operatorname{var}\left(b_{1}\right)+4 \text { PHomeWin }{ }^{2} \operatorname{var}\left(b_{2}\right)+4 \text { PHomeWin cov }\left(b_{1}, b_{2}\right)\right]^{1 / 2}
$$

in which $b_{1}$ and $b_{2}$ are the point estimates on PHomeWin and PHomeWin ${ }^{2}$ respectively, and $\operatorname{var}\left(b_{1}\right), \operatorname{var}\left(b_{2}\right)$ and $\operatorname{cov}\left(b_{1}, b_{2}\right)$ are the estimated cluster-robust variances and covariance of the relevant estimated parameters (Aiken and West, 1991). The point estimates and confidence intervals for the marginal effect for the model in Table 2, column (1) are represented graphically in Figure 2. This shows that increasing the home-win probability has a statistically significant positive marginal effect on match attendance up to approximately a value of PHomeWin of 0.5 . Thereafter, the marginal effect, including beyond the turning point in the relationship between $\ln$ (Attendance) and PHomeWin, is not 
statistically significantly different from zero. The results obtained therefore provide relatively modest support for the $\mathrm{UOH}$ with respect to match uncertainty.

The estimated coefficient on home-team success is positive and statistically significant at the 0.1 per cent level. The point estimate suggests that a three-match increase in WinStreak increases attendance by $11.4 \%$. The estimated average effect of winning the premiership in the previous season is an increase in attendance of approximately $17 \%$. Each of these estimated effects assumes other things are equal; for a team with a successful run of wins, consequent improvements in strength ratings and league standing also enhance the probabilities of winning matches and of making the playoffs.

The coefficients on Round and its squared value are both statistically significant at the $0.01 \%$ level and imply initially declining attendance as the season progresses, with a turning point after 14 rounds. This pattern is consistent with heightened early-season interest in matches, followed by a fall-off in interest and then a revival towards the end of the season.

Matches involving two Sydney-based teams have statistically and quantitatively significantly higher attendance, whereas rain, showers or windy weather, on average, have negative effects on attendance. Attendance in 2005 and 2008 (the NRL's centenary year) was on average higher than in the base year of 2004. Mid-week matches (Tuesday and Wednesday) attract statistically significantly higher attendance (compared to Monday matches). The identity of the away team also has statistically significant effects on attendance (not reported in Table 2) with several teams drawing significantly lower crowds, other things equal, compared to the base category team, the Broncos. Some significant 
time-of-day effects are also found (primarily negative effects from later kick-off times in the afternoon compared to noon, other things equal).

Given the marginal significance of the terms in the quadratic formulation involving the PHomeWin in Table 2, column (1), we experimented with alternative measures of match uncertainty. Columns (2) to (4) report results using Excite50 (defined as $0.5-\mid 0.5-$ PHomeWin $\mid$ ), Excite60 (defined as $0.6-\mid 0.6-$ PHomeWin) $\mid$ ) and MatchUnbal (defined as $\mid \ln ($ PHomeWin/(1 - PHomeWin $)) \mid)$. None of these alternative formulations has a statistically significant coefficient at the 5\% level, although the coefficient on Excite60 is significant at the $10 \%$ level. $^{27}$

In Table 3, we report results using alternative measures of playoff uncertainty: the number of points the home team is behind the current leader (HomePtsBack) in column (1), HomePtsBack and the number of points the away team is behind the current leader (AwayPtsBack) in column (2), the average of number of points the home and away teams are behind the current leader (AvPtsBack) in column (3), and the number of points the home team requires to make the playoffs (PtsRequired) in column (4). Each of the four measures of playoff uncertainty has the expected coefficient sign and each is highly statistically significant. Varying the definition of the playoff uncertainty measure has little effect on the size and significance of the coefficients on other variables, except for changes in the marginal significance level of PHomeWin. These results suggest that all the measures examined are capturing, in different ways, the statistically significant effects of playoff uncertainty on match attendance.

\footnotetext{
${ }^{27}$ Excite50 and Excite60 have maximum values at home-win probabilities of 0.5 and 0.6 respectively, the latter closely corresponding to the turning point of the quadratic relationship in Table 2, column (1).
} 


\section{Conclusions}

The simulation-based approach adopted in this paper to generate measures of uncertainty of outcome in modelling sports attendance produces promising results. It has several appealing features compared to existing ad hoc methods of characterizing seasonal or playoff uncertainty; in particular, it provides a consistent set of playoff probabilities across all teams that reflects the strength of the past and future schedules and uses a wider set of relevant ex ante information than just current league standings. It would be feasible to apply this approach in a range of different league settings to evaluate the attendance implications of different aspects of competition design, such as different playoff structures or multiple prizes (e.g., avoiding relegation and/or qualification for other competitions, such as in European football).

The results obtained for the NRL suggest that playoff uncertainty is a more significant driver of attendance than individual match uncertainty. Although we have characterized existing points-behind-based measures of playoff uncertainty as relatively crude, and their marginal levels of statistical significance are not quite as impressive as the simulationbased measures, they do appear to capture important elements of playoff uncertainty. Hence, to the extent that the NRL experience is representative, the use of such measures in other attendance demand studies may not have seriously misrepresented the role of playoff uncertainty. In keeping with existing results for other sports, consistent winning performances have a quantitatively greater effect on attendance than uncertainty measures. Overall, the various estimated effects reflecting the home team's past win performances and enhanced probabilities of match and playoff success combine to produce a virtuous cycle that improves match attendance. 


\section{REFERENCES}

Aiken, L.S. and West, S.G. (1991), Multiple Regression: Testing and Interpreting Interactions. Sage, London.

Alchin, T.M. and Tranby, H.W. (1995), 'Does the Louis-Schmelling Paradox Exist in Rugby League match attendances in Australia?', University of Western Sydney, Nepean, Working Papers in Economics, No. WP95/09.

Baimbridge, M., Cameron, S. and Dawson, P. (1995), 'Satellite Broadcasting and Match Attendance: The Case of Rugby League', Applied Economics Letters, 2, 343-46.

Baimbridge, M., Cameron, S. and Dawson, P. (1996), 'Satellite Television and the Demand for Football: A Whole New Ball Game', Scottish Journal of Political Economy, 43, 317-33.

Baum, C.F. (2001), 'Residual Diagnostics for Cross-Section Time Series Regression Models', Stata Journal, 1, 101-4.

Benz, M.-A., Brandes, L. and Franck, E. (2009), 'Do Soccer Associations Really Spend on a Good Thing? Empirical Evidence on Heterogeneity in the Consumer Response to Match Uncertainty of Outcome', Contemporary Economic Policy, 27, 216-35.

Bojke, C. (2008), 'The Impact of Post-Season Play-Off Systems on the Attendance at Regular Season Games', in Albert, J. and Koning, R.H. (eds), Statistical Thinking in Sports. Chapman \& Hall/CRC Press, Boca Raton, FL; 179-202.

Booth, R. (2004), 'The Economics of Achieving Competitive Balance in the Australian Football League, 1897-2004', Economic Papers, 23, 325-44.

Borland, J. (1987), 'The Demand for Australian Rules Football', Economic Record, 63, 220-30. Borland, J. and Lye, J. (1992), 'Attendance at Australian Rules Football: A Panel Study', Applied Economics, 24, 1053-8. 
Borland, J. and Macdonald, R. (2003), 'Demand for Sport', Oxford Review of Economic Policy, $19,478-502$.

Breusch, T.S. and Pagan, A.R. (1980), 'The Lagrange Multiplier Test and its Applications to Model Specification in Econometrics', Review of Economic Studies, 47, 239-53.

Buraimo, B., Forrest, D. and Simmons, R. (2008), 'Outcome Uncertainty Measures: How Closely Do They Predict a Close Game?', in Albert, J. and Koning, R.H. (eds), Statistical Thinking in Sports. Chapman \& Hall/CRC Press, Boca Raton, FL; 167-78.

Cairns, J.A., Jennett, N. and Sloane, P.J. (1986), 'The Economics of Professional Team Sports: A Survey of Theory and Evidence', Journal of Economic Studies, 13, 3-80.

Carmichael, F., Millington, J. and Simmons, R. (1999), 'Elasticity of Demand for Rugby League Attendance and the Impact of BSkyB', Applied Economics Letters, 6, 797-800.

Clarke, S.R. (1993), 'Computer Forecasting of Australian Rules Football for a Daily Newspaper', Journal of the Operational Research Society, 44, 753-9.

Clarke, S.R. (2005), 'Home Advantage in the Australian Football League', Journal of Sports Sciences, 23, 375-85.

Czarnitzki, D. and Stadtmann, G. (2002), 'Uncertainty of Outcome Versus Reputation: Empirical Evidence for the First German Football Division', Empirical Economics, 27, 10112.

De Hoyos, R.E. and Sarafidis, V. (2006), 'Testing for Cross-Sectional Dependence in PanelData Models', Stata Journal, 6, 482-496.

Dobson, S. and Goddard, J. (2008), 'Forecasting Scores and Results and Testing the Efficiency of the Fixed-Odds Betting Market in Scottish League Football', in Albert, J. and Koning, R.H. (eds), Statistical Thinking in Sports. Chapman \& Hall/CRC Press, Boca Raton, FL; 91109. 
Dobson, S., Goddard, J. and Wilson, J.O.S. (2001), 'League Structure and Match Attendances in English Rugby League', International Review of Applied Economics, 15, 335-51.

Downward, P. and Dawson, A. (2000), The Economics of Professional Team Sports. Routledge, London.

Downward, P., Dawson, A. and Dejonghe, T. (2009), Sports Economics: Theory, Evidence and Policy. Butterworth-Heinemann/Elsevier, Oxford.

Falter, J.-M. and Pérignon, C. (2000), 'Demand for Football and Intramatch Winning Probability: An Essay on the Glorious Uncertainty of Sports', Applied Economics, 32, 175765.

Forrest, D. and Simmons, R. (2002), 'Outcome Uncertainty and Attendance Demand in Sport: The Case of English Soccer', Journal of the Royal Statistical Society, Series D (The Statistician), 51, 229-41.

Forrest, D., Beaumont, J., Goddard, J. and Simmons, R. (2005), 'Home Advantage and the Debate about Competitive Balance in Professional Sports Leagues', Journal of Sports Sciences, 23, 439-45.

García, J. and Rodríguez, P. (2002), 'The Determinants of Football Match Attendance Revisited: Empirical Evidence from the Spanish Football League', Journal of Sports Economics, 3, 18-38.

Guggenberger, P. (2010), 'The Impact of a Hausman Pretest on the Size of a Hypothesis Test: The Panel Data Case', Journal of Econometrics, 156, 337-43.

Hart, R.A., Hutton, J. and Sharot, T. (1975), 'A Statistical Analysis of Association Football Attendances', Journal of the Royal Statistical Society, Series C (Applied Statistics), 24, 1727.

Jennett, N. (1984), 'Attendances, Uncertainty of Outcome and Policy in Scottish League Football', Scottish Journal of Political Economy, 31, 176-98. 
Jones, J.C.H., Schofield, J.A. and Giles, D.E.A. (2000), 'Our Fans in the North: The Demand for British Rugby League', Applied Economics, 32, 1877-87.

Knowles, G., Sherony, K. and Haupert, M. (1992), 'The Demand for Major League Baseball: A Test of the Uncertainty of Outcome Hypothesis', The American Economist, 36, 72-80.

Koning, R.H., Koolhaas, M., Renes, G. and Ridder, G. (2003), 'A Simulation Model for Football Championships', European Journal of Operational Research, 148, 268-76.

Lee, Y.H. (2009), 'The Impact of Postseason Restructuring on the Competitive Balance and Fan Demand in Major League Baseball’, Journal of Sports Economics, 10, 219-35.

Lemke, R.J., Leonard, M. and Tlhokwane, K. (2010), 'Estimating Attendance at Major League Baseball Games for the 2007 Season', Journal of Sports Economics, 11, 316-48.

Lenten, L.J.A. (2009a), 'Unobserved Components in Competitive Balance and Match Attendances in the Australian Football League, 1945-2005: Where is all the Action Happening?', Economic Record, 85, 181-96.

Lenten, L.J.A. (2009b), 'Towards a New Dynamic Measure of Competitive Balance: A Study Applied to Australia's Two Major Professional 'Football' Leagues', Economic Analysis and Policy, 39, 407-28.

Madalozzo, R. and Villar, R.B. (2009), 'Brazilian Football: What Brings Fans to the Game?', Journal of Sports Economics, 10, 639-50.

Meehan, J.W., Jr., Nelson, R.A. and Richardson, T.V. (2007), 'Competitive Balance and Game Attendance in Major League Baseball', Journal of Sports Economics, 8, 563-80.

Peel, D. and Thomas, D. (1988), 'Outcome Uncertainty and the Demand for Football: An Analysis of Match Attendances in the English Football League', Scottish Journal of Political Economy, 35, 242-9.

Peel, D.A. and Thomas, D.A. (1992), 'The Demand for Football: Some Evidence on Outcome Uncertainty', Empirical Economics, 17, 323-31. 
Pesaran, M.H. (2004), 'General Diagnostic Tests for Cross Section Dependence in Panels', CESifo Working Paper No. 1229.

Rottenberg, S. (1956), 'The Baseball Players' Labor Market', Journal of Political Economy, $64,242-58$.

Sandy, R., Sloane, P.J., Rosentraub, M.S. (2004), The Economics of Sport: An International Perspective. Palgrave Macmillan, Basingstoke.

Stefani, R. and Clarke, S. (1992), 'Predictions and Home Advantage for Australian Rules Football', Journal of Applied Statistics, 19, 251-61.

Szymanski, S. (2003), 'The Economic Design of Sporting Contests', Journal of Economic Literature, 41, 1137-87.

Welki, A.M. and Zlatoper, T.J. (1999), 'U.S. Professional Football Game-Day Attendance', Atlantic Economic Journal, 27, 285-98.

Whitney, J.D. (1988), 'Winning Games Versus Winning Championships: The Economics of Fan Interest and Team Performance', Economic Inquiry, 26, 703-24.

Wilson, P. and Sim, B. (1995), 'The Demand for Semi-Pro League Football in Malaysia 198991: A Panel Data Approach', Applied Economics, 27, 131-8.

Wooldridge, J.M. (2002), Econometric Analysis of Cross Section and Panel Data. MIT Press, Cambridge, MA. 
TABLE 1

Summary Statistics for Key Variables

\begin{tabular}{lcccc}
\hline & Mean & Std Dev & Min & Max \\
\hline lnAttendance & 9.576 & 0.413 & 8.340 & 10.832 \\
PHomeWin & 0.590 & 0.168 & 0.101 & 0.944 \\
PHomePlayoff & 0.550 & 0.389 & 0 & 1 \\
PAwayPlayoff & 0.535 & 0.392 & 0 & 1 \\
WinStreak & 0.910 & 1.459 & 0 & 11 \\
PrevYrWin & 0.065 & 0.247 & 0 & 1 \\
Round & 13.451 & 7.535 & 1 & 26 \\
Sydney & 0.207 & 0.405 & 0 & 1 \\
\hline
\end{tabular}


TABLE 2

Fixed Effects Estimation Results with Alternative Match Uncertainty Measures

\begin{tabular}{|c|c|c|c|c|}
\hline & (1) & (2) & (3) & (4) \\
\hline PHomeWin & $\begin{array}{l}0.753^{*} \\
(2.18)\end{array}$ & & & \\
\hline PHomeWin ${ }^{2}$ & $\begin{array}{c}-0.622 \\
(2.03)\end{array}$ & & & \\
\hline PHomePlayoff & $\begin{array}{l}0.194^{* * *} \\
(8.53)\end{array}$ & $\begin{array}{l}0.204^{* * * *} \\
(9.46)\end{array}$ & $\begin{array}{l}0.196^{* * *} \\
(9.51)\end{array}$ & $\begin{array}{l}0.205^{* * *} \\
(9.34)\end{array}$ \\
\hline PAwayPlayoff & $\begin{array}{l}0.106^{* * *} \\
(5.01)\end{array}$ & $\begin{array}{l}0.0962^{* *} \\
(3.87)\end{array}$ & $\begin{array}{l}0.103^{* * *} \\
(4.35)\end{array}$ & $\begin{array}{l}0.0947^{* *} \\
(3.87)\end{array}$ \\
\hline WinStreak & $\begin{array}{l}0.0381^{* * *} \\
(4.48)\end{array}$ & $\begin{array}{l}0.0387^{* * *} \\
(4.25)\end{array}$ & $\begin{array}{l}0.0383^{* * *} \\
(4.32)\end{array}$ & $\begin{array}{l}0.0390^{* * *} \\
(4.35)\end{array}$ \\
\hline PreviousYrWin & $\begin{array}{l}0.168^{* * *} \\
(4.35)\end{array}$ & $\begin{array}{l}0.173^{* * *} \\
(4.47)\end{array}$ & $\begin{array}{l}0.169^{* * *} \\
(4.38)\end{array}$ & $\begin{array}{l}0.174^{* * *} \\
(4.47)\end{array}$ \\
\hline Excite 50 & & $\begin{array}{l}0.120 \\
(1.32)\end{array}$ & & \\
\hline Excite60 & & & $\begin{array}{c}0.208 \\
(1.82)\end{array}$ & \\
\hline MatchUnbal & & & & $\begin{array}{c}-0.0291 \\
(1.56)\end{array}$ \\
\hline Round & $\begin{array}{l}-0.0512^{* * *} \\
(9.33)\end{array}$ & $\begin{array}{l}-0.0511^{* * *} \\
(9.49)\end{array}$ & $\begin{array}{l}-0.0513^{* * *} \\
(9.45)\end{array}$ & $\begin{array}{l}-0.0511^{* * *} \\
(9.41)\end{array}$ \\
\hline Round $^{2}$ & $\begin{array}{l}0.00176^{* * *} \\
(8.00)\end{array}$ & $\begin{array}{l}0.00175^{* * *} \\
(8.10)\end{array}$ & $\begin{array}{l}0.00176^{* * *} \\
(8.09)\end{array}$ & $\begin{array}{l}0.00175^{* * *} \\
(8.05)\end{array}$ \\
\hline Sydney & $\begin{array}{c}0.121^{*} \\
(2.23)\end{array}$ & $\begin{array}{c}0.120^{*} \\
(2.23)\end{array}$ & $\begin{array}{l}0.121^{*} \\
(2.24)\end{array}$ & $\begin{array}{l}0.120^{*} \\
(2.24)\end{array}$ \\
\hline Hot & $\begin{array}{l}0.0216 \\
(0.18)\end{array}$ & $\begin{array}{l}0.0182 \\
(0.16)\end{array}$ & $\begin{array}{l}0.0229 \\
(0.19)\end{array}$ & $\begin{array}{l}0.0173 \\
(0.15)\end{array}$ \\
\hline Overcast & $\begin{array}{l}-0.0150 \\
(0.25)\end{array}$ & $\begin{array}{l}-0.0147 \\
(0.24)\end{array}$ & $\begin{array}{l}-0.0147 \\
(0.24)\end{array}$ & $\begin{array}{l}-0.0144 \\
(0.24)\end{array}$ \\
\hline Windy & $\begin{array}{c}-0.109^{* *} \\
(3.29)\end{array}$ & $\begin{array}{c}-0.109^{* *} \\
(3.32)\end{array}$ & $\begin{array}{l}-0.108^{* *} \\
(3.32)\end{array}$ & $\begin{array}{c}-0.109^{* *} \\
(3.30)\end{array}$ \\
\hline Rain & $\begin{array}{l}-0.242^{* * *} \\
(4.27)\end{array}$ & $\begin{array}{c}-0.242^{* * *} \\
(4.27)\end{array}$ & $\begin{array}{c}-0.241^{* * *} \\
(4.27)\end{array}$ & $\begin{array}{c}-0.242^{* * *} \\
(4.27)\end{array}$ \\
\hline Showers & $\begin{array}{l}-0.188^{* * *} \\
(6.27)\end{array}$ & $\begin{array}{l}-0.191^{* * *} \\
(6.54)\end{array}$ & $\begin{array}{l}-0.189^{* * *} \\
(6.30)\end{array}$ & $\begin{array}{l}-0.191^{* * *} \\
(6.56)\end{array}$ \\
\hline Cold & $\begin{array}{l}-0.0559 \\
(1.21)\end{array}$ & $\begin{array}{l}-0.0582 \\
(1.24)\end{array}$ & $\begin{array}{l}-0.0552 \\
(1.19)\end{array}$ & $\begin{array}{l}-0.0577 \\
(1.24)\end{array}$ \\
\hline 2005 & $\begin{array}{l}0.0944^{* *} \\
(3.59)\end{array}$ & $\begin{array}{c}0.100^{* *} \\
(3.68)\end{array}$ & $\begin{array}{l}0.0960^{* *} \\
(3.45)\end{array}$ & $\begin{array}{l}0.101^{* *} \\
(3.74)\end{array}$ \\
\hline 2006 & $\begin{array}{l}0.00890 \\
(0.27)\end{array}$ & $\begin{array}{l}0.0170 \\
(0.54)\end{array}$ & $\begin{array}{l}0.0111 \\
(0.33)\end{array}$ & $\begin{array}{l}0.0172 \\
(0.54)\end{array}$ \\
\hline 2007 & $\begin{array}{l}0.00630 \\
(0.17)\end{array}$ & $\begin{array}{l}0.0106 \\
(0.29)\end{array}$ & $\begin{array}{l}0.00768 \\
(0.21)\end{array}$ & $\begin{array}{l}0.00919 \\
(0.25)\end{array}$ \\
\hline
\end{tabular}




\begin{tabular}{lcccc}
2008 & $0.0772^{*}$ & $0.0863^{*}$ & $0.0790^{*}$ & $0.0860^{*}$ \\
Tues & $(2.49)$ & $(2.65)$ & $(2.47)$ & $(2.64)^{* * *}$ \\
& $0.873^{* * *}$ & $0.862^{* * *}$ & $0.870^{* * *}$ & $0.863^{* *}$ \\
Wed & $(6.27)$ & $(6.22)$ & $(6.30)$ & $(6.23)^{* *}$ \\
& $0.516^{* *}$ & $0.494^{* *}$ & $0.517^{* *}$ & $0.495^{* *}$ \\
Fri & $(3.94)$ & $(3.76)$ & $(4.00)$ & $(3.77)$ \\
& -0.160 & -0.145 & -0.165 & -0.147 \\
Sat & $(0.68)$ & $(0.62)$ & $(0.69)$ & $(0.63)$ \\
& -0.285 & -0.273 & -0.291 & -0.274 \\
Sun & $(1.20)$ & $(1.16)$ & $(1.22)$ & $(1.16)$ \\
& -0.0666 & -0.0774 & -0.0670 & -0.0755 \\
Constant & $(0.72)$ & $(0.83)$ & $(0.72)$ & $(0.81)$ \\
& $9.666^{* * *}$ & $9.844^{* * *}$ & $9.767^{* * *}$ & $9.902^{* * *}$ \\
\hline$R^{2}$ & $(79.05)$ & $(86.62)$ & $(84.63)$ & $(83.54)$ \\
Normality- $p$ & 0.697 & 0.696 & 0.697 & 0.696 \\
Hetero- $p$ & 0.186 & 0.225 & 0.207 & 0.233 \\
BP-LM-p & 0.000 & 0.000 & 0.000 & 0.000 \\
Pesaran CD-p & 0.128 & 0.113 & 0.134 & 0.112 \\
AvAbsCross & 0.504 & 0.442 & 0.447 & 0.478 \\
Auto-p & 0.128 & 0.127 & 0.128 & 0.127 \\
Notes: The & 0.239 & 0.301 & 0.344 & 0.268
\end{tabular}

Notes: The dependent variable is $\ln$ (Attendance). Absolute $t$-statistics, based on cluster-robust standard errors, are reported in parentheses. ${ }^{*},{ }^{* *}$ and ${ }^{* * *}$ denote significance at the $5 \%, 1 \%$ and $0.1 \%$ levels respectively. Dummy variables for away teams and time of kick-off are included in the models but estimates are not reported; full results are available on request. $N=924$ for all models. $R^{2}$ values are obtained from equivalent least-squares dummy variable regressions that include the home-team fixed effects. Suffix $p$ denotes $p$-values reported for diagnostic tests. Normality is a chisquared test for normality, Hetero is a modified Wald test for groupwise heteroskedasticity, BP-LM is the BreuschPagan (1980) LM test for cross-sectional independence of the errors, Pesaran CD is Pesaran's (2004) cross-sectional dependence test, Auto is Wooldridge's (2002) test for first-order autocorrelation, and AvAbsCross is the average absolute value of the off-diagonal elements in the matrix of residuals. 
TABLE 3

Fixed Effects Estimation Results with Alternative Playoff Uncertainty Measures

\begin{tabular}{|c|c|c|c|c|}
\hline \multirow{3}{*}{ PHomeWin } & (1) & (2) & (3) & (4) \\
\hline & 0.699 & 0.771 & $0.863^{*}$ & 0.607 \\
\hline & (1.95) & $(2.12)$ & $(2.20)$ & $(1.73)$ \\
\hline \multirow[t]{2}{*}{ PHomeWin ${ }^{2}$} & $-0.665^{*}$ & -0.655 & -0.656 & -0.604 \\
\hline & (2.18) & $(2.05)$ & (1.96) & (2.03) \\
\hline HomePtsBack & $\begin{array}{l}-0.0156^{* * *} \\
(6.53)\end{array}$ & $\begin{array}{l}-0.0142^{* * *} \\
(5.55)\end{array}$ & & \\
\hline AwayPtsBack & & $\begin{array}{l}-0.00592^{*} \\
(2.77)\end{array}$ & & \\
\hline AvPtsBack & & & $\begin{array}{l}-0.0198^{* * *} \\
(7.58)\end{array}$ & \\
\hline PtsRequired & & & & $\begin{array}{l}-0.0224^{* * *} \\
(6.50)\end{array}$ \\
\hline \multirow[t]{2}{*}{ WinStreak } & $0.0358^{* *}$ & $0.0356^{* *}$ & $0.0383^{* * *}$ & $0.0339^{* *}$ \\
\hline & $(3.85)$ & (3.91) & $(4.21)$ & (3.77) \\
\hline PreviousYrWin & $\begin{array}{l}0.158^{* *} \\
(3.27)\end{array}$ & $\begin{array}{l}0.154^{* *} \\
(3.11)\end{array}$ & $\begin{array}{l}0.147^{*} \\
(2.94)\end{array}$ & $\begin{array}{l}0.152^{* *} \\
(3.21)\end{array}$ \\
\hline Round & $\begin{array}{l}-0.0423^{* * *} \\
(7.78)\end{array}$ & $\begin{array}{l}-0.0401^{* * *} \\
(7.69)\end{array}$ & $\begin{array}{l}-0.0408^{* * *} \\
(8.01)\end{array}$ & $\begin{array}{l}-0.0782^{* * *} \\
(9.61)\end{array}$ \\
\hline Round $^{2}$ & $\begin{array}{l}0.00169^{* * *} \\
(7.91)\end{array}$ & $\begin{array}{l}0.00170^{* * *} \\
(7.96)\end{array}$ & $\begin{array}{l}0.00172^{* * *} \\
(8.10)\end{array}$ & $\begin{array}{l}0.00190^{* * *} \\
(7.87)\end{array}$ \\
\hline Constant & $\begin{array}{l}10.02^{* * *} \\
(63.72)\end{array}$ & $\begin{array}{l}9.919^{* * *} \\
(63.83)\end{array}$ & $\begin{array}{c}9.824^{* * *} \\
(65.18)\end{array}$ & $\begin{array}{l}10.64^{* * *} \\
(50.46)\end{array}$ \\
\hline$R^{2}$ & 0.685 & 0.687 & 0.685 & 0.691 \\
\hline Normality- $p$ & 0.075 & 0.044 & 0.035 & 0.074 \\
\hline Hetero- $p$ & 0.000 & 0.000 & 0.000 & 0.000 \\
\hline$B P-L M-p$ & 0.177 & 0.225 & 0.331 & 0.035 \\
\hline Pesaran $C D-p$ & 0.185 & 0.077 & 0.097 & 0.482 \\
\hline AvAbsCross & 0.122 & 0.120 & 0.118 & 0.127 \\
\hline Auto-p & 0.228 & 0.122 & 0.117 & 0.293 \\
\hline
\end{tabular}

Note: see Notes to Table 2. Dummy variables for weather characteristics, Sydney teams, year and day effects, away teams and time of kick-off are included in the models, but estimates are not reported; full results are available on request. 
FIGURE 1

Heterogeneity in $\ln$ (Attendance) Across Home Teams

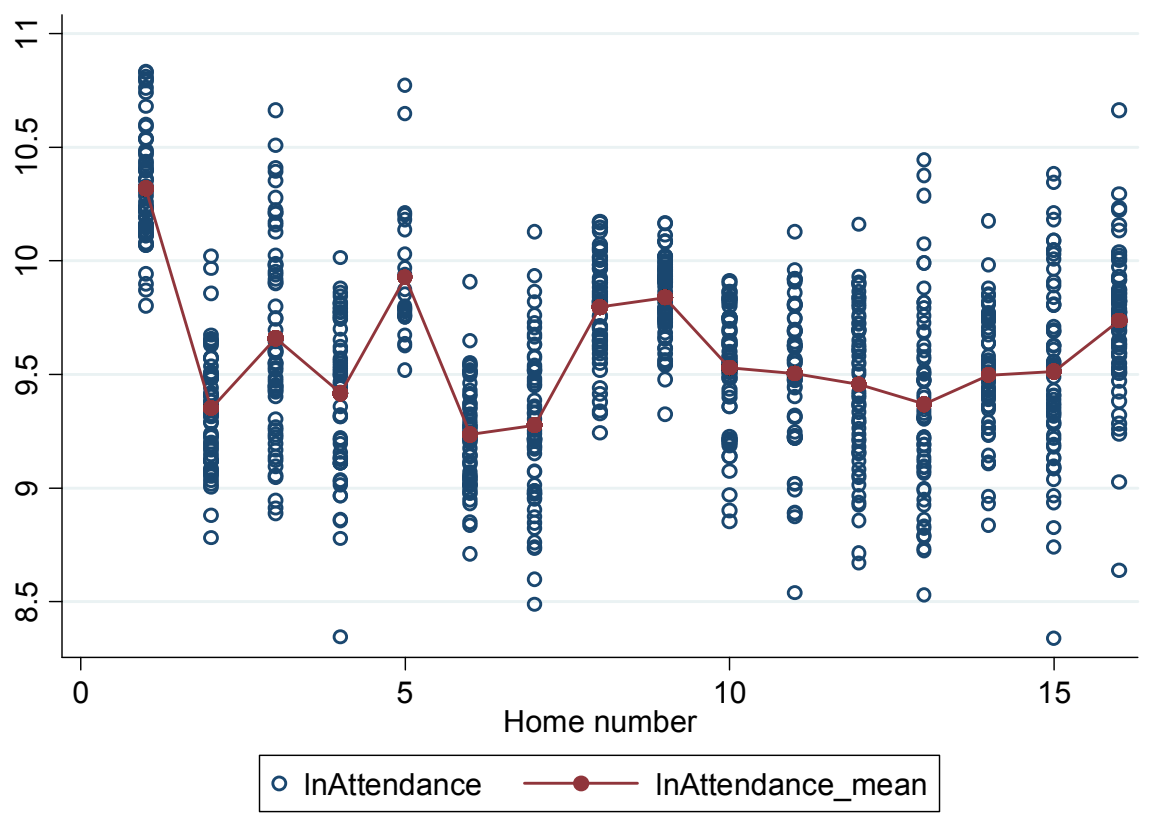

FIGURE 2

Marginal Effect of Simulated PHomeWin on $\ln ($ Attendance)

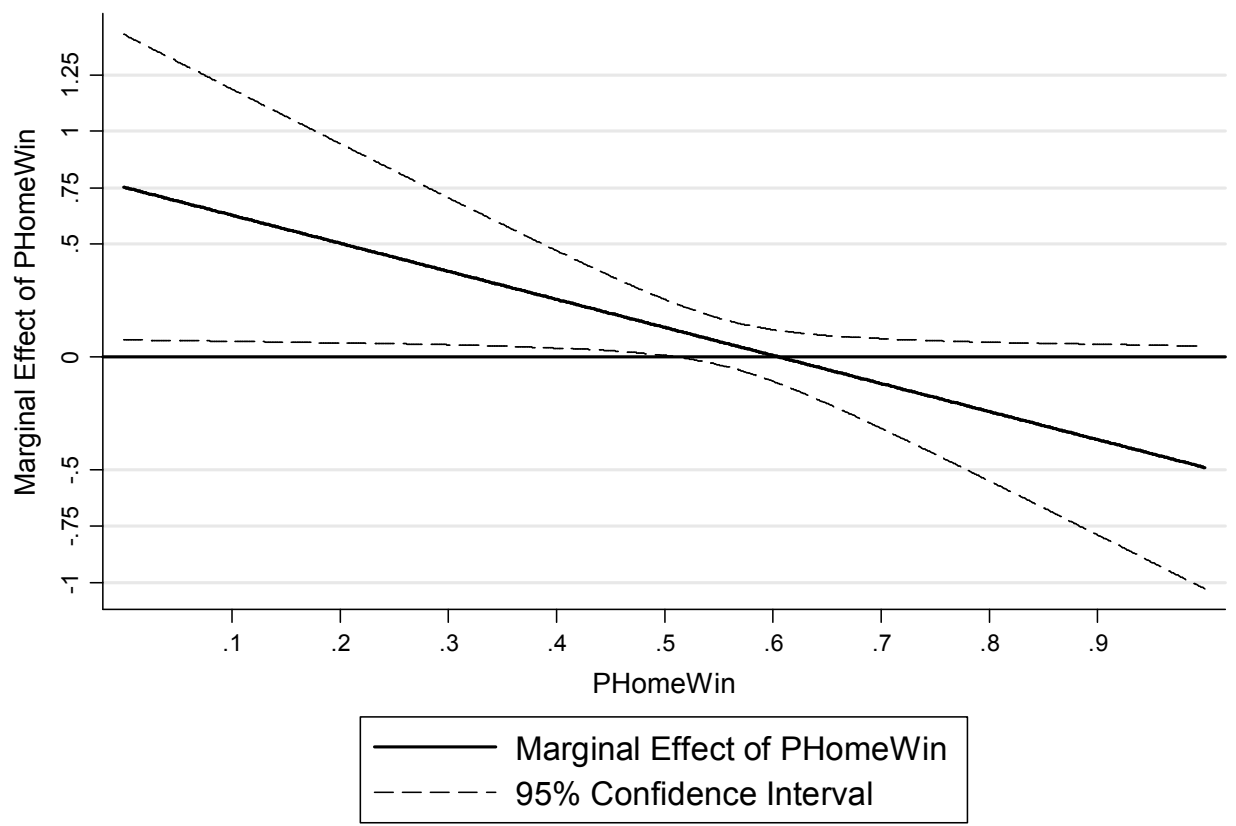

